\title{
SIMULTANEOUS PARAMETRIC OPTIMIZATION OF MICRO- EDM DRILLING OF BRASS C360 USING TAGUCHI BASED GREY RELATION ANALYSIS
}

\author{
Pranav Kumar $^{1}-$ L. N. Pattanaik ${ }^{2 *}-$ R. K. Singh ${ }^{3}$
}

${ }^{1}$ Department of Production Engineering, Birla Institute of Technology, Mesra, Ranchi, India 835215

${ }^{2,3}$ Department of Production Engineering, Birla Institute of Technology, Mesra, Ranchi, India 835215

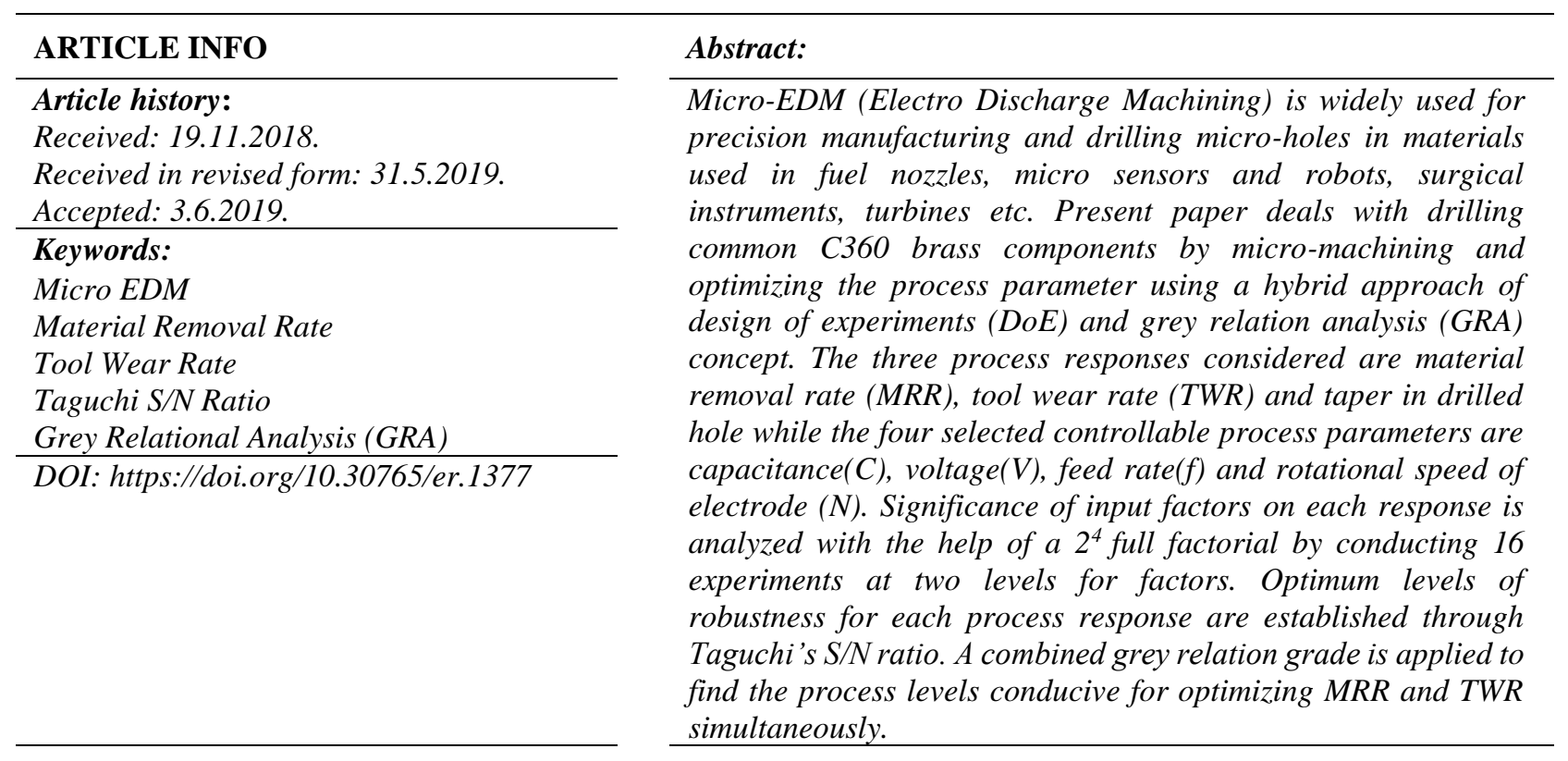

\section{Introduction and related literature}

Development of miniaturized products with multiple functions requires advancement in micro manufacturing techniques. Micro EDM is an unconventional thermo-electric process which gives liberty to machine any conducting and semi conducting material regardless of its rigidity with respect to tool. This process has an extensive variety of applications in industries as it is capable of producing intricate shapes at micro level as in micro-electro-mechanical systems (MEMS). It is a non-contact process and thus the problems related to impact forces of the tool on workpiece are not applicable. Researchers are continuously working towards bringing more innovations into micro-EDM process and to enhance the machining efficiency of it. Machining of conductive materials like aluminium alloys, stainless steel, titanium and its alloys, tungsten and Inconel alloys have been a great research interest. Similarly, machining of non-conducting materials like zirconia, silicon carbide and many other ceramics is being done by micro-EDM using additive electrode technique to enhance the machining efficiency. The shape, size and material of electrodes are also being investigated to increase performance of the process. Electrodes of different shapes are being used to improve the flushing ability of dielectric fluid. Different shapes of electrodes like helical, tubular, cylindrical, orbital and planetary are developed for improving the MRR and decreasing the wear of electrode. The electrical resistivity and thermal conductivity also contribute to TWR and MRR. More research on dielectric fluids are found as they are responsible for flushing away of debris which affects the surface quality and MRR.

Process parameter have significant role in controlling and increasing the machining efficiency of a micro EDM process. Many researchers have explored different process parameters on which micro-EDM

\footnotetext{
* Corresponding author

Email address: Inpattanaik@bitmesra.ac.in
} 
performance depends. Some of the major influencing input parameters are electrode materials, size and shape of tool electrode, capacitance, voltage, feed rate, rotational speed of electrode, types of dielectric fluid, polarity of workpiece etc. Urso and Merla (2014) studied the effects of various workpiece and electrode influence on micro-EDM drilling performances.

Bhosle and Sharma (2017) investigated to find out a unique optimal parameter setting for micro-EDM drilling process of Inconel alloy with tungsten carbide electrode of $500 \mu \mathrm{m}$. It was found through ANOVA analysis that capacitance and voltage are the two most significant parameters and feed rate is the least important process parameter. However, feed rate plays an important role in controlling taper angle. In another work by Shuliang et al. (2017) high aspect ratio micro-holes are drilled using micro-EDM on C17200 beryllium copper alloy.

Fu et al. (2016) have focused their work on two major problems associated with micro-EDM; slow machining rate and high tool wear. The electrodes of pure tungsten and tungsten carbide were compared for tool wear with respect to two different dielectric fluids; oil and deionized water. They reported that tungsten has much smaller tool wear compared to tungsten carbide in both the dielectric fluids.

Urso et al. (2016) studied the influence of electrode material in micro EDM drilling of stainless steel and tungsten carbide materials. ANOVA was conducted to find that peak current, voltage and frequency as the influencing parameters for MRR and TWR both. Brass electrodes always resulting in higher MRR compared to tungsten carbide. Rasheed et al. (2013) reported their work on micro EDM of Ni-Ti alloys using a full factorial design. They found capacitance and discharge voltage as the most significant factors which influences the MRR and circularity of holes. In case of brass tool material, the rate of erosion was higher compared to tungsten. Also, surface roughness of work was found to be better at lower discharge energy when using tungsten carbide electrode.

Banu et al. (2014) discussed the machining of non-conducting zirconia ceramic on micro-EDM with tungsten electrode. Three arrangements for assisting electrode were used to investigate this process; gold coating foil, copper adhesive and the combination of both. With gold coating foil of thickness $5 \mathrm{pm}$, minor machining marks are seen on the work. The conclusion was drawn that high conductivity generates high amount of heat between the gap which enhances MRR.

Micro-EDM drilling process on Inconel 718 superalloy with copper-tungsten electrode was conducted by Ay et.al. (2013). Grey regression analysis was applied to analyze the multi-performance parameters. They found that pulse current has a more significant effect on the dimensional accuracy of the drilled hole than pulse duration. It was also reported that electrode wear increases with decrease in discharge current and when the pulse duration is short. Plaza et al. (2014) reported an experimental study on micro EDM-drilling of Ti6Al4V using helical electrodes.

Jahan et al. (2015) studied the influence of the process parameters on the micro-EDM performance on tungsten carbide work with a tungsten electrode. It was found that for negative polarity of electrode, MRR is high and TWR is low. The surface finish and dimensional accuracy increased with increase in resistance. With an increase in pulse duration, MRR increased whereas TWR first decreased and then increases. With the increase in rotational speed of electrode, MRR increased and TWR decreased. Albert and Chang (2016) in their work developed a hybrid micro-EDM grinding of micro-holes using Ni-Co/diamond co-deposition. Mustufa et al. (2018) solved a multi-objective optimization problem on micro-EDM of nickel-titanium-based shape memory alloy. Hasan et al. (2017) published a comprehensive review of literature on various micro drilling techniques available till date.

Based on the review of literature, it is observed that micro holes created by $\mu$-EDM process need to be investigated further for taperness, optimum MRR and TWR on brass material and brass as electrode. The objective of the paper is to implement a simultaneous optimization of multiple responses like MRR, TWR and taperness during the micro drilling operation of C360 brass using grey relation analysis. The optimum levels for four input factors namely capacitance (C), voltage (V), feed rate (f) and rotational speed of electrode $(\mathrm{N})$ are to be established through Taguchi's $\mathrm{S} / \mathrm{N}$ ratio to minimise the effect of noise on the multiple responses.

In this paper, section 2 gives description on experimental set up including tool preparation, work piece material, machines and measuring instruments used. Section 3 contains the experimental data collected through design of experiment (DOE), Taguchi analysis and grey relational analysis to identify the optimum levels for the process parameters. Conclusion and future scopes are presented in the last section. 


\section{Experimental Procedure}

\subsection{The micro-EDM machine}

The micro-EDM processes for the present work are carried out in a hybrid machine (MIKROTOOL ${ }^{\circledR}$ DT110 hybrid, Figure 1) capable of performing multiple operations at micro level. Various operations that DT110 hybrid micro-EDM can perform are die-sinking EDM, wire EDM, wire Electro-Discharge Grinding (WEDG) and micro-drilling-turning-milling.

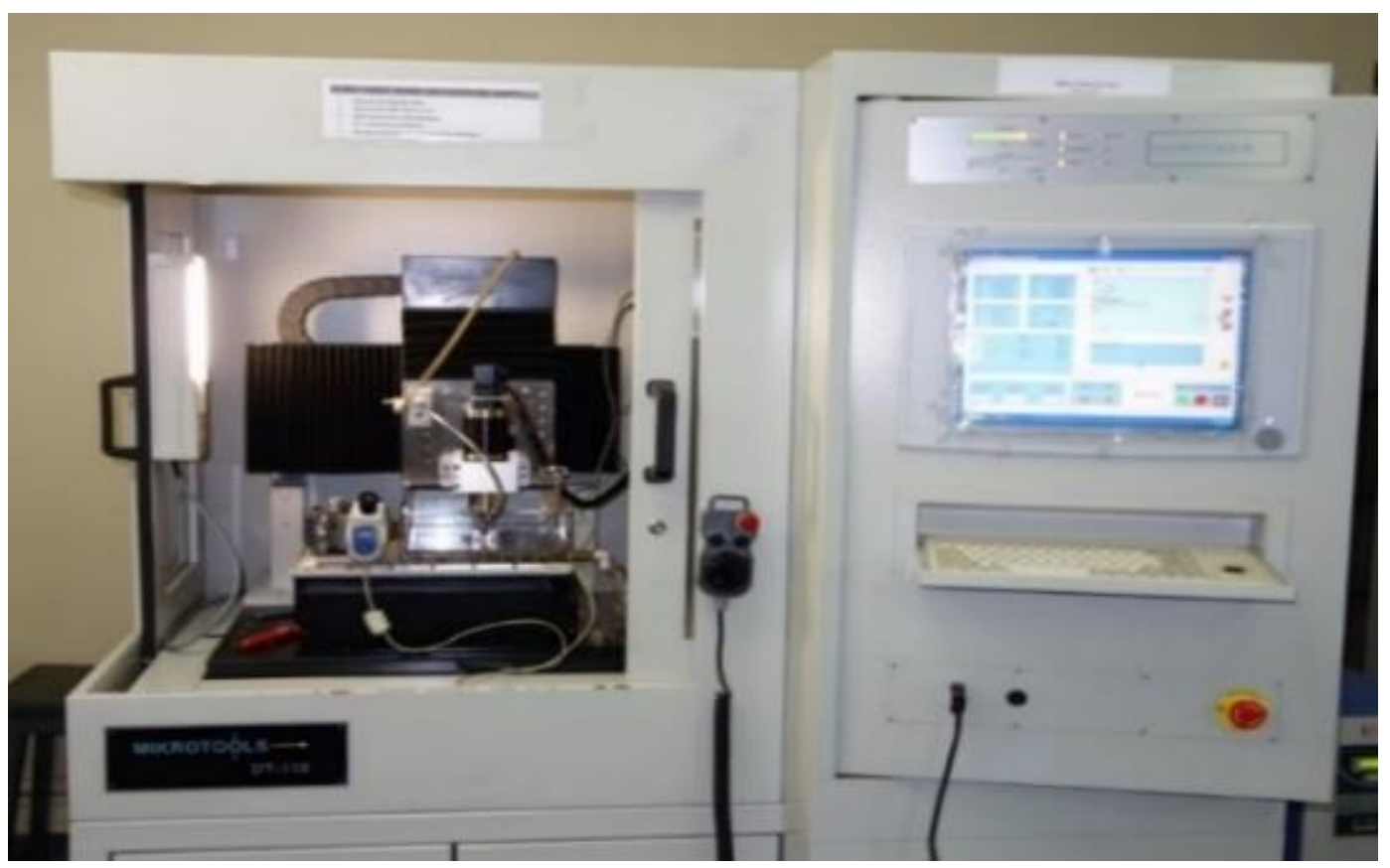

Figure 1. MIKROTOOL ${ }^{\circledR}$ DT-110 hybrid machine.

Some vital technical specifications for the machine are as follows:

Machine travels: X-200mm, Y-100mm, Z-100mm

Position accuracy: $\pm 1 \mu / 100 \mathrm{~mm}$

Position feedback scale: Optical linear scale with resolution of $0.1 \mu \mathrm{m}$

Spindle speed range: 0-3000 RPM

EDM Power supply: Voltage 80-150V RC, Discharge circuit-1 $\Omega$ fixed

Capacitance: $1-6 \mathrm{pF}$ (selectable)

Slide straightness: $+1-2$ micron $/ 100 \mathrm{~mm}, \pm 0.5$ micron over travel of $25 \mathrm{~mm}$

The DT-110 hybrid micro-EDM is a computer numerically controlled machine which works on GM codes. For the experiments, electrode is machined on the hybrid machine itself for performing drilling operations. Other auxiliary equipment and measuring devices used for the present experiments are optical microscope, digital vernier calliper, multi-meter and weighing scale.

\subsection{Preparation of work and tool}

Micro drilling operation is to be performed on work piece of brass C360 using electrode of the same material. The work material is of high electrical conductivity and corrosion resistant used for manufacturing of sensors and MEMS (Micro-Electrical Mechanical Systems) applications. For this experiment, a thin sheet of dimension $20 \times 20 \times 0.3 \mathrm{~mm}$ is used. The composition and some relevant property constants for the work material brass $\mathrm{C} 360$ are given in Table 1 . 
Table 1. Composition and constants for work material.

\begin{tabular}{c|c}
\hline Brass C360 & \%age \\
\hline $\mathrm{Sn}$ & $<0.05$ \\
$\mathrm{~Pb}$ & $<3.0$ \\
$\mathrm{Al}$ & $<0.02$ \\
$\mathrm{Fe}$ & $<0.35$ \\
$\mathrm{Zn}$ & $<35.0$ \\
$\mathrm{Ni}$ & $<0.2$ \\
$\mathrm{Cu}$ & remainder \\
\hline Young's modulus (in $\mathrm{MPa})$ & 251 \\
\hline Yield stress (in MPa) & 337 \\
\hline Thermal conductivity $\mathrm{W} /(\mathrm{m} \cdot \mathrm{K})$ & 124 \\
\hline Electrical conductivity $($ in $\%)$ & IACS 27 \\
\hline
\end{tabular}

The work piece is mounted on the machine with the help of a magnetic fixture. The work is set to positive and tool as negative polarity during the process. After every machining the electrode tip is cleaned with cotton bud dipped in acetone. After finishing the drilling operation, the work is cleaned with acetone which removes the black patches formed due to machining. The dielectric fluid applied is EDM Oil with viscosity of $7.0 \mathrm{~mm}^{2} / \mathrm{s}$ at $20^{\circ} \mathrm{C}$ and auto ignition temperature of $470{ }^{\circ} \mathrm{F}$.

Micro tools are prepared by turning the $\mathrm{C} 360$ brass rod of $\phi 4 \mathrm{~mm}$ on the hybrid micro machine using the same spindle which is used to perform milling. Figure 2 (a) shows the built-in camera image of turning operation. For this experiment, electrode of $\phi 300 \mu$ are turned from $\phi 4 \mathrm{~mm}$. The electrode diameter is measured using the coordinate axes (X and $\mathrm{Y}$ ) as displayed in Figure 2 (a). MRR for the turning process is kept low as it has to be performed with great care to avoid failures. Figure 2 (b) shows brass C360 electrode of 300 microns.

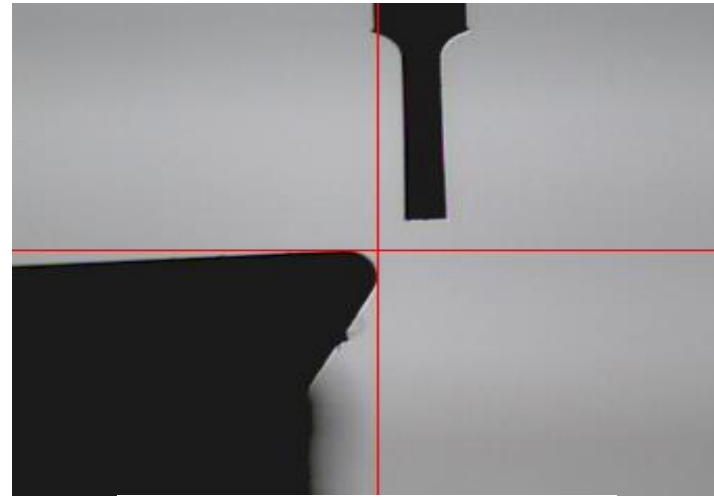

(a) Turning of micro tool

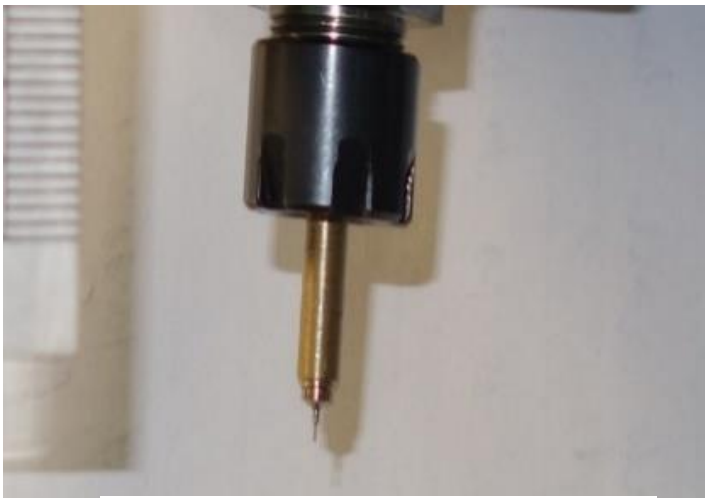

(b) Electrode of C360 brass

Figure 2. Preparation of electrode using turning on hybrid micro machining.

\section{Design of Experiment}

\subsection{Factors and responses}

The experimental design is based on the objectives of identifying significant factors affecting the three responses of the process namely MRR, TWR and taperness of the drilled hole followed by Taguchi and GRA based optimization of process outputs. The three responses are selected for this work based on an extensive literature review, wherein majority of the researchers considered these as essential for a micro-EDM drilling process. The three process outputs are briefly introduced here.

Material removal rate or MRR is the rate of metal erosion that takes place from work piece during machining. It is desirable to achieve higher MRR thus reducing the machining time. It normally depends on the type of work material, tool electrode and the machining parameters such as capacitance, voltage, feed rate, dielectric medium, temperature, tool speed, polarity etc. Typical material removal rates range from 0.1 to $400 \mathrm{~mm}^{3} / \mathrm{min}$. 
The MRR is calculated using Eq. (1), as the ratio of average volume of material removed to the operation time which can be expressed as $\mathrm{mm}^{3} / \mathrm{min}$.

$$
\operatorname{MRR}\left(\text { in } \frac{\mathrm{mm}^{3}}{\min }\right)=\frac{(\text { Initial weight }- \text { Final weight }) \text { of work }}{(\text { Machining time } \times \text { Density of work material })}
$$

The density of brass C360 work material is $0.00873 \mathrm{gm} / \mathrm{mm}^{3}$.

Tool wear rate or TWR is the rate of wear or erosion of the electrode tool during the machining. The objective is to minimize this detrimental wear to avoid frequent tool changes and dimensional inaccuracies in work. TWR is expressed as in Eq. (2) in terms of the ratio of weight of the tool material eroded over the entire machining time.

$$
T W R\left(\text { in } \frac{g m}{\min }\right)=\frac{\left(6.17 \times 10^{-4}\right)(\text { Initial height }- \text { Final height }) \text { of tool in } \mathrm{mm}}{\text { Machining time (in } \mathrm{min})}
$$

The multiplicative constant $6.17 \times 10^{-4}$ in the numerator is the product of cross-sectional area of the cylindrical electrode $0.07068 \mathrm{~mm}^{2}$ and density of the material $0.00873 \mathrm{gm} / \mathrm{mm}^{3}$.

Taperness in the drilled holes is expressed as the difference between the entry diameter and exit diameter over the depth. The accuracy and precision of a micro hole is evaluated through the taperness. Equation (3) is applied to measure the taperness in a hole.

$$
\text { Taperness }=\frac{\left(\mathrm{D}_{\text {Entry }}-\mathrm{D}_{\text {Exit }}\right) \text { in } m m}{2(\text { Depth of hole in } m m)}
$$

Similarly, the input process parameters selected on the basis of several published research works are capacitance, voltage, feed rate and rotational speed of electrode. Full factorial $2^{4}$ or 16 experiments are conducted with two levels for each factor. The level settings for the four factors along with their measuring units and symbols are presented in Table 2.

Table 2. Process parameters and their level settings.

\begin{tabular}{ccccc}
\hline Process parameters & Unit & Symbol & Level 1 & Level 2 \\
\hline Capacitance & $\mathrm{pF}$ & $\mathrm{C}$ & 2 & 6 \\
Voltage & $\mathrm{Volt}$ & $\mathrm{V}$ & 90 & 130 \\
Feed rate & $\mu \mathrm{m} / \mathrm{sec}$ & $\mathrm{F}$ & 0.1 & 1.0 \\
Rotation speed of electrode & $\mathrm{RPM}$ & $\mathrm{N}$ & 1000 & 3000 \\
\hline
\end{tabular}

\subsection{Experimental data and analysis}

In order to ascertain the significance of the four input process parameters on the three performance measures, a full factorial design of experiments consisting of 16 trials is conducted at the designated setting for the levels. As presented in Table 3, MRR, TWR and Taperness are calculated using eq. (1), (2) and (3) for each of the experiment. (-1) and (1) indicates the lower and upper levels for the process parameters respectively. The significance of the four selected input parameters is tested individually on each response using MINITAB ${ }^{\circledR}$ (ver. 17) software.

The Pareto chart of the standardized effects for main factors without interaction terms on the responses are depicted in Figure 3. At significance level of $\alpha$ as 0.1 , the vertical Pareto line intersects the factors $\mathrm{C}$ and $\mathrm{F}$ for both the responses MRR and TWR. This indicates the statistical significance of these factors on the responses. However, as shown in Figure 3 (c), these four input factors are not affecting the taperness of the drilled holes. Hence, the response of taperness is excluded from the subsequent optimization approach. 
Table 3. Full factorial experiment results for three outputs.

\begin{tabular}{|c|c|r|r|r|c|c|c|}
\hline Ex. No. & $\mathbf{C}$ & $\mathbf{V}$ & $\mathbf{F}$ & $\mathbf{N}$ & $\begin{array}{c}\text { MRR } \\
\left(\mathrm{mm}^{3} / \mathrm{min}\right)\end{array}$ & TWR (gm/min) & $\begin{array}{c}\text { Taperness } \\
(\mathrm{mm})\end{array}$ \\
\hline 1 & -1 & -1 & -1 & -1 & 0.0008 & 0.0050 & 0.0001 \\
\hline 2 & 1 & -1 & -1 & -1 & 0.0143 & 0.0048 & 0.0000 \\
\hline 3 & 1 & -1 & 1 & -1 & 0.0049 & 0.0009 & 0.0001 \\
\hline 4 & 1 & 1 & 1 & -1 & 0.0047 & 0.0036 & 0.0000 \\
\hline 5 & 1 & 1 & 1 & 1 & 0.0054 & 0.0040 & 0.0001 \\
\hline 6 & 1 & 1 & -1 & -1 & 0.0114 & 0.0156 & 0.0008 \\
\hline 7 & -1 & 1 & 1 & 1 & 0.0012 & 0.0008 & 0.0011 \\
\hline 8 & -1 & 1 & 1 & -1 & 0.0004 & 0.0002 & 0.0001 \\
\hline 9 & -1 & 1 & -1 & 1 & 0.0002 & 0.0001 & 0.0001 \\
\hline 10 & 1 & 1 & -1 & 1 & 0.0270 & 0.0107 & 0.0000 \\
\hline 11 & -1 & -1 & 1 & 1 & 0.0007 & 0.0001 & 0.0001 \\
\hline 12 & -1 & -1 & -1 & 1 & 0.0016 & 0.0004 & 0.0001 \\
\hline 13 & -1 & -1 & 1 & -1 & 0.0004 & 0.0002 & 0.0012 \\
\hline 14 & 1 & -1 & 1 & 1 & 0.0057 & 0.0021 & 0.0013 \\
\hline 15 & 1 & -1 & -1 & 1 & 0.0135 & 0.0081 & 0.0013 \\
\hline 16 & -1 & 1 & -1 & -1 & 0.0003 & 0.0004 & 0.0009 \\
\hline
\end{tabular}

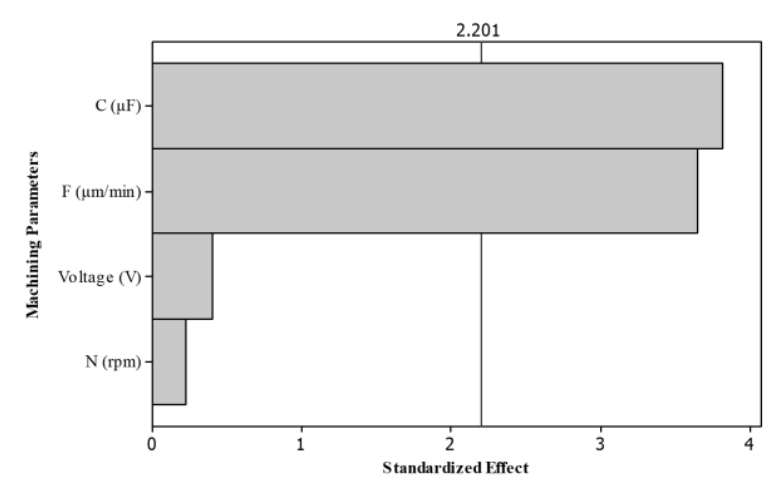

(a) Effect on MRR

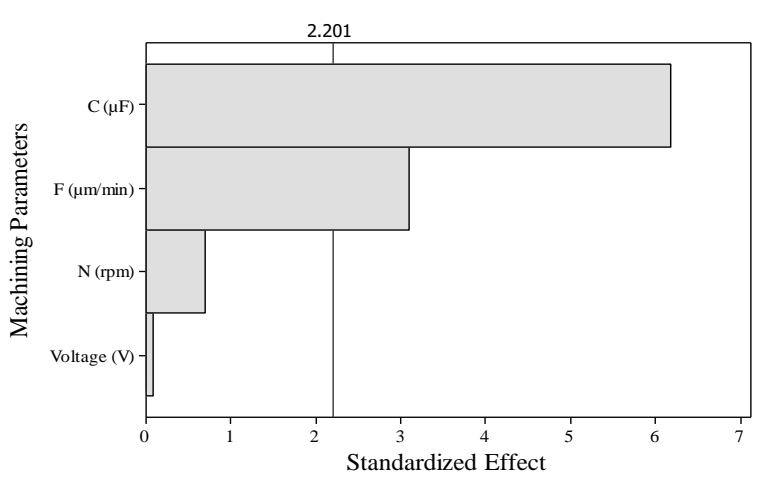

(b) Effect on TWR

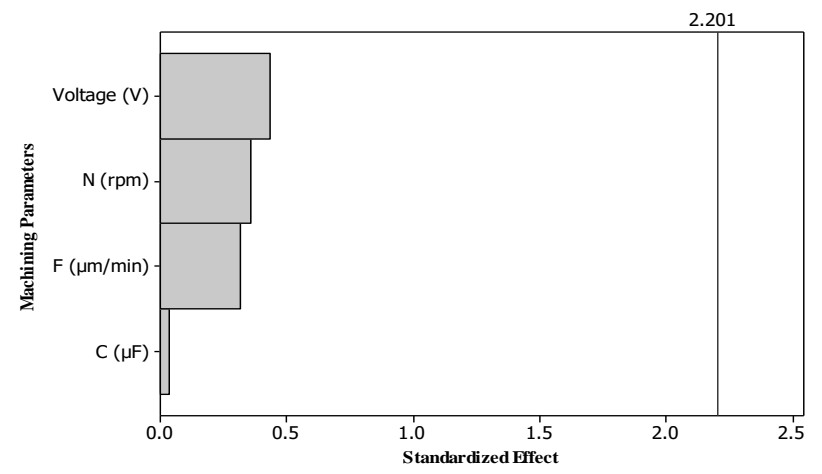

(c) Effect on Taperness

Figure 3. Significant effect of four input factors on responses found by vertical Pareto line.

\subsection{Robust design for responses}

In robust design, uncontrollable noise factors are considered to find the optimal levels for each controllable factor to reduce the harmful effects of noises. In other words the process becomes robust or insensitive to noises that causes unwanted variations in the responses. Noises cannot be eliminated but their effects can be 
minimized. Noise factors are purposely varied during the experimentation to cause variations in response in order to find the level of control factors that minimizes the variation. Taguchi used the concept of Signal-toNoise (S/N) ratio to find these best levels for each controllable factors (Montgomery, 2003).

The two responses MRR and TWR are selected from the previous section for further statistical analysis using Taguchi based robust design. It is an off-line quality engineering approach where uncontrollable noise factors are considered to find the optimal levels for each controllable factor to reduce the harmful effects of noises. The same full factorial experimental data is used to find the optimum levels for four input factors to minimize the effects of noise on MRR and TWR separately. MINITAB ${ }^{\circledR}$ is used to create response tables, main effects and S/N ratios plots for MRR as larger-is-better and TWR as smaller-is-better objectives.

\begin{tabular}{ccccc}
\hline Level & $\mathrm{C}$ & $\mathrm{V}$ & $\mathrm{F}$ & $\mathrm{N}$ \\
\hline 1 & -64.1296 & -51.5584 & -50.2507 & -54.0227 \\
2 & -40.8787 & -53.4500 & -54.7576 & -50.9857 \\
Delta & 23.2510 & 1.8916 & 4.5069 & 3.0370 \\
\hline Rank & 1 & 4 & 2 & 3 \\
\hline \multicolumn{5}{c}{ Main Effects Plot for S/N Ratios }
\end{tabular}

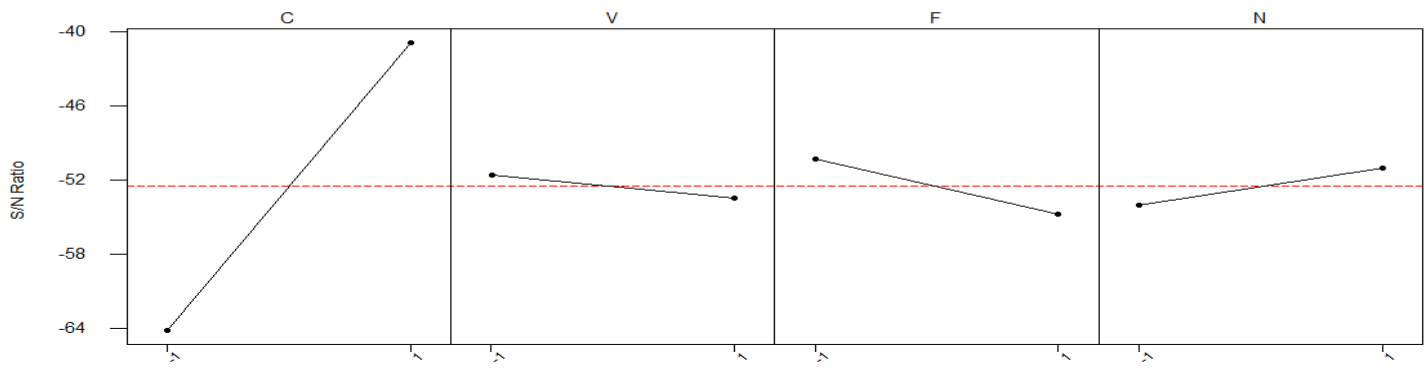

Figure 4. Ranking of input parameters in response table and main effect plot for (larger-thebetter)S/N ratio of MRR.

\begin{tabular}{ccccc}
\hline Level & $\mathrm{C}$ & $\mathrm{V}$ & $\mathrm{F}$ & $\mathrm{N}$ \\
\hline 1 & 68.1461 & 58.5744 & 52.5728 & 56.4993 \\
2 & 46.7829 & 56.3546 & 62.3563 & 58.4297 \\
Delta & 21.3632 & 2.2198 & 9.7835 & 1.9304 \\
\hline Rank & 1 & 3 & 2 & 4 \\
\hline \multicolumn{5}{c}{ Main Effects Plot for S/N Ratios }
\end{tabular}

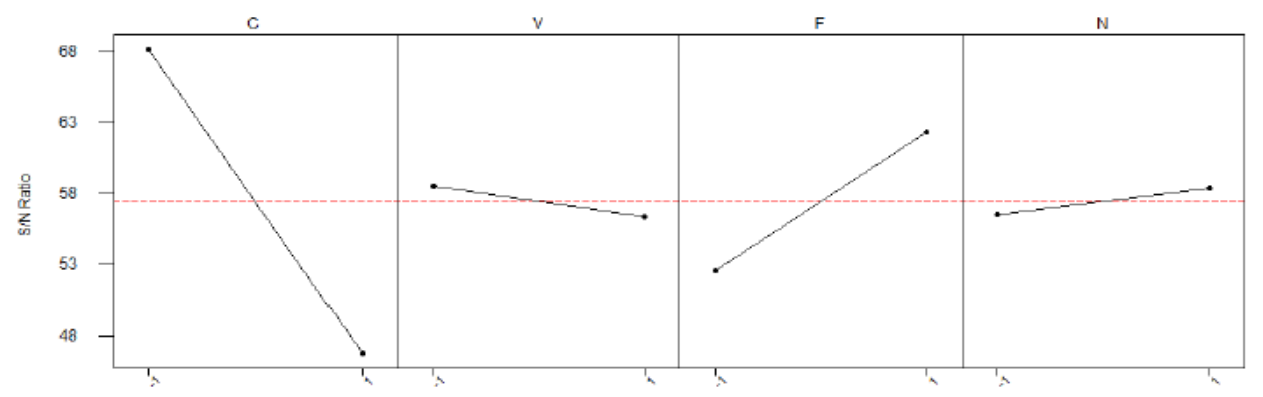

Figure 5. Ranking of input parameters in response table and main effect plot for (smaller-thebetter) $S / N$ ratio of TWR. 
As evident from the response table for $\mathrm{S} / \mathrm{N}$ ratio, capacitance $(\mathrm{C})$ is the main factor which substantially affects the response MRR followed by feed rate. Further, referring to Figure 4, the optimum levels for these factors to minimize the effects of noise on MRR are C (level 2), F (level 1), N (level 2) and V (level 1). Similarly, referring to Figure 5, the optimum levels for the four factors are found for the response TWR as C (level 1), F (level 2), N (level 2) and V (level 1).

\subsection{Application of GRA}

Taguchi based optimization is considered to be suitable only for single objective problems in identifying the factor levels that maximizes the signal-to-noise $(\mathrm{S} / \mathrm{N})$ ratio. In the case multiple responses as here, the optimal factor levels selected through Taguchi S/N ratio for one response may not be the best levels for other responses. In order to address this issue, grey relational analysis (GRA) based on grey system theory is the most widely used one.

The GRA approach contains various steps to finally find the grey grade which is used as the combined response (Deng 1989, Lin and Lin 2002). This methodology converts the different objective quality parameters into single objective quality parameter.

The grey relational grade which has maximum value is the optimal result for different responses. However, the calculations in these steps are carried out manually as statistical software has not incorporated the GRA feature yet. Normalized values for each response are calculated where 'higher-the-better' condition is used for MRR and 'lower-the-better' for TWR.

After finding the $\mathrm{S} / \mathrm{N}$ ratios for all the responses, they are normalized to bring them into a range of 0 to 1 . For normalization the following relations (4) and (5) are used for larger-the-better (MRR) and Smaller-the-better (TWR) respectively:

$$
\begin{gathered}
\text { Normalized value of } Y_{i}=\frac{Y_{i}-Y_{i}(\min )}{Y_{i}(\max )-Y_{i}(\min )} \\
\text { Normalized value of } Y_{i}=\frac{Y_{i}(\max )-Y_{i}}{Y_{i}(\max )-Y_{i}(\min )}
\end{gathered}
$$

Then the grey relational coefficients (GC) are calculated as explained here.

$$
G C=\frac{\left(\Delta_{\min }+\alpha \Delta_{\max }\right)}{\left(\Delta_{i}+\alpha \Delta_{\max }\right)}
$$

Where $\Delta$ represents a term similar to Taguchi's 'quality loss' and are found as the difference between the highest normalized value of 1 and a given normalized S/N ratio (Deng, 1989). 
Table 4. Grey relation coefficients and grades.

\begin{tabular}{|c|c|c|c|c|c|c|}
\hline $\begin{array}{c}\text { Ex. } \\
\text { No. }\end{array}$ & $\begin{array}{c}\text { Normalized } \\
\text { MRR }\end{array}$ & $\begin{array}{c}\text { Normalized } \\
\text { TWR }\end{array}$ & GRC MRR & GRC TWR & $\begin{array}{c}\text { GR } \\
\text { Grade }\end{array}$ & Rank \\
\hline 1 & 0.022 & 0.683 & 0.338 & 0.612 & 0.475 & 15 \\
\hline 2 & 0.524 & 0.693 & 0.512 & 0.619 & 0.566 & 11 \\
\hline 3 & 0.173 & 0.947 & 0.376 & 0.905 & 0.641 & 8 \\
\hline 4 & 0.169 & 0.771 & 0.375 & 0.686 & 0.530 & 12 \\
\hline 5 & 0.195 & 0.748 & 0.383 & 0.665 & 0.524 & 13 \\
\hline 6 & 0.417 & 0 & 0.461 & 0.333 & 0.397 & 16 \\
\hline 7 & 0.036 & 0.954 & 0.341 & 0.917 & 0.629 & 9 \\
\hline 8 & 0.006 & 0.992 & 0.334 & 0.985 & 0.660 & 5 \\
\hline 9 & 0 & 0.996 & 0.333 & 0.993 & 0.663 & 3 \\
\hline 10 & 1 & 0.319 & 1 & 0.423 & 0.711 & 1 \\
\hline 11 & 0.016 & 1 & 0.337 & 1 & 0.668 & 2 \\
\hline 12 & 0.051 & 0.979 & 0.345 & 0.960 & 0.652 & 6 \\
\hline 13 & 0.007 & 0.993 & 0.334 & 0.986 & 0.660 & 4 \\
\hline 14 & 0.204 & 0.869 & 0.385 & 0.793 & 0.589 & 10 \\
\hline 15 & 0.495 & 0.481 & 0.497 & 0.490 & 0.494 & 14 \\
\hline 16 & 0.004 & 0.980 & 0.334 & 0.961 & 0.647 & 7 \\
\hline
\end{tabular}

The grey relation grade (GRG) as found in Table 4 is a consolidation of both MRR and TWR responses. Now the GRG is treated as a single response in Taguchi based robust design to find the optimum levels for each factors.

\begin{tabular}{ccccc}
\hline Level & $\mathrm{C}$ & $\mathrm{V}$ & $\mathrm{F}$ & $\mathrm{N}$ \\
\hline 1 & -4.02764 & -4.59616 & -4.94033 & -4.96798 \\
2 & -5.19764 & -4.62912 & -4.28495 & -4.25730 \\
Delta & 1.17000 & 0.03296 & 0.65538 & 0.71068 \\
\hline Rank & 1 & 4 & 3 & 2 \\
\hline \multicolumn{5}{c}{ Main Effects Plot for S/N Ratios }
\end{tabular}

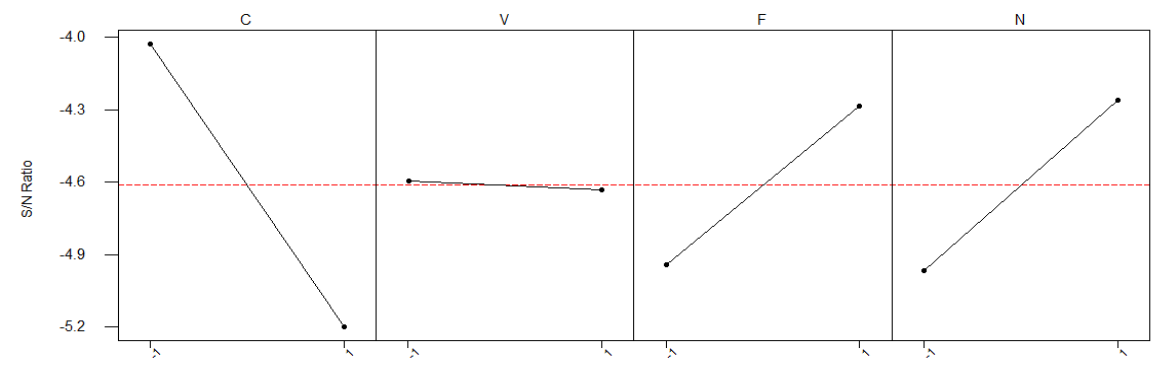

Figure 6. Final ranking of input parameters in response table and main effect plot for (larger-the-better) S/N ratio of GRG.

As produced in Figure 6, the response table and main effect plot for $\mathrm{S} / \mathrm{N}$ ratio of GRG shows that the significance of the factors in the descending order is capacitance, rotational speed of the electrode, feed rate and voltage. From the S/N ratio plot, the optimum levels for the factors are identified as capacitance (level 1), $\mathrm{N}$ (level 2), F (level 2) and V (level 1). 


\section{Conclusion}

In this paper, drilling operation of common C360 brass components by micro-machining and optimization of the process parameter using a hybrid approach of Taguchi and grey relation analysis is presented. The three process responses considered initially are material removal rate, tool wear rate and taper in drilled hole. The four selected controllable process parameters were capacitance, voltage, feed rate and rotational speed of electrode. Significance of input factors on each response is analyzed with the help of a full factorial by conducting 16 experiments at two levels for factors. Based on the results, taper in hole was excluded from the study as the factors were insignificant. Optimum levels for process parameters and their significance ranks were established for each of the remaining two responses through Taguchi's $\mathrm{S} / \mathrm{N}$ ratio. Then a combined grey relation grade is applied to find the process levels conducive for optimizing both MRR and TWR simultaneously. The ranking for the four input factors based on delta-value was obtained as capacitance (Rank 1), electrode RPM (Rank 2), feed rate (Rank 3) and voltage (Rank 4). Further, the optimum levels for these parameters to achieve robustness are also found from grey based $\mathrm{S} / \mathrm{N}$ ratio. These levels are level 1, level 2, level 2 and level 1 for the controllable factors $\mathrm{C}, \mathrm{N}, \mathrm{F}$ and $\mathrm{V}$ respectively.

In order to establish a holistic empirical relation among process parameters with responses, more controllable factors can be included in the study and the design of experiment should be conducted after discarding insignificant factors. Apart from drilling, other operations can be investigated using electrodes with helical and square profiles.

\section{Acknowledgements}

The authors wish to thank the two anonymous referees for their valued review and suggestions to improve the content and presentation of the paper.

\section{References}

[1] Albert Wen-Jeng Hsue and Yu-Fu Chang. (2016). Toward synchronous hybrid micro-EDM grinding of micro-holes using helical taper tools formed by Ni-Co/diamond Co-deposition. Journal of Materials Processing Technology,234, 368-382.

[2] Ay, M., Caydas, U. and Hascalik A. (2013). Optimization of micro-EDM drilling of Inconel 718 superalloy. International Journal of Advanced Manufacturing Technology, 66, 1015-1023.

[3] Banu, A., Ali, M.Y. and Rahman, M.A. (2014). Micro-Electro Discharge Machining of non-conductive zirconia ceramic: Investigation of MRR \& recast layer hardness. International Journal of Advanced Manufacturing Technology, 75, 257-267.

[4] Bhosle, R.B. and Sharma, S.B. (2017), Multi-performance optimization of micro-EDM drilling process of Inconel 600 alloy. Materials Today: Proceedings, 4, 1988-1997.

[5] Deng, J. L. (1989). Introduction to grey system theory. The Journal of grey system, 1(1), 1-24.

[6] Fu, Y., Takumu, M., Wataru, N., Wansheng, Z. and Zuyuan, Y. (2016), Study on Influence of Electrode Material on Hole Drilling in Micro-EDM, Procedia CIRP, 42, 516-520.

[7] G.D'Urso and C. Merla. (2014). Workpiece and electrode influence on micro-EDM drilling performance. Precision Engineering, 38, 903-914.

[8] Jahan, M. P., Kakavand, P., Kwang, E. L. M., Rahman, M. and Wong, Y. S. (2015). An experimental investigation into the micro-electro-discharge machining behaviour of aluminium alloy (AA 2024). International Journal of Advanced Manufacturing Technology, 78:1127-1139.

[9] Lin, J. L., and Lin, C. L. (2002). The use of the orthogonal array with grey relational analysis to optimize the electrical discharge machining process with multiple performance characteristics. International Journal of Machine Tools and Manufacture, 42(2), 237-244.

[10] Mahadi Hasan, Jingwei Zhao and Zhengyi Jiang. (2017). A review of modern advancements in micro drilling techniques. Journal of Manufacturing Processes, 29, 343-375.

[11] Montgomery, D. C. (2003). Design and Analy-sis of Experiments, John Wiley \& Sons.

[12] Mustufa H. Abidi, Abdulrahman M. Al-Ahmari, Usama Umer and Mohammed Sarvar Rasheed. (2018). Multi-objective optimization of micro-electrical discharge machining of nickel-titanium-based shape memory alloy using MOGA-II. Measurement,125, 336-349. 
[13] Rasheed, Abidi, Bdulazi, A. and Al-hmaril. (2013) Investigation of Micro-EDM input Parameters on Various Outputs in Machining Ni-Ti Shape Memory Alloy Using Full Factorial Design, Advanced Materials Research, Vols. 816-1 120131 173-1 79

[14] Shuliang Dong, Zhenlong Wang and Yukui Wang Jiazhang (2017). Micro-EDM drilling of high aspect ratio micro-holes and in situ surface improvement in C17200 beryllium copper alloy. Journal of Alloys and Compounds, 727, 1157-1164.

[15] Soraya Plaza, Jose A. Sanchez, Endika Perez, Ruben Gil, Borja Izquierdo Naiara, Ortega Inigo Pombo. (2014) Experimental study on micro EDM-drilling of Ti6A14V using helical electrode. Precision Engineering, 38(4), 821-827.

[16] Urso, G., Maccarini, G. and Ravasio, C. (2016). Influence of electrode material in micro-EDM drilling of stainless steel and tungsten carbide. International Journal of Advanced Manufacturing Technology, $85,2013-2025$. 